\title{
CRÍTICA A LA INTERVENCIÓN EN EL YACIMIENTO ARQUEOLÓGICO DE LA CASA BODEGA Y QUADRA ${ }^{(*)}$
}

\author{
CRITIQUE TO THE INTERVENTION IN THE ARCHAEOLOGICAL SITE \\ OF THE BODEGA Y QUADRA HOUSE \\ ROLANDO ARCIGA SOTO ${ }^{[\star *+}$
}

Fecha de recepción: 30 de agosto de 2016

Fecha de aprobación: 26 de noviembre de 2016

\section{RESUMEN}

La intervención realizada en la casa Bodega y Quadra en el Centro Histórico de Lima-Perú(***) es el único caso contemporáneo de un museo de sitio en esta parte de la ciudad donde se aprecia un yacimiento arqueológico de la época colonial. La intervención realizada tiene muchos aspectos estratégicos, entre los cuales algunos resaltan, como la decisión política de la gestión de la Municipalidad Metropolitana de Lima de crear el museo de sitio; la ubicación favorable del inmueble en el corazón mismo del Centro Histórico de Lima, acorde a la preservación o conservación ambiental; y el mantenimiento del lazo entre el yacimiento y sus piezas a través del museo de sitio, gracias a lo cual se le da el uso más adecuado al monumento según indica la teoría de la Restauración Objetiva. Se trata de una intervención en el área arqueológica que mayoritariamente fue respetuosa de los principios de la restauración científica contemporánea.

\section{PALABRAS CLAVE}

Crítica patrimonial, casa Bodega y Quadra, intervención

\section{ABSTRACT}

The intervention of the Bodega y Quadra House in the Historic Center of Lima-Perú is the only contemporary case of a site museum in this part of the city where an archaeological site of the colonial era can be observed. The intervention has many key aspects, among which some are particularly salient, such as the political decision of the Municipalidad Metropolitana de Lima to create the museum; its favorable location in the heart of the historic city center itself, which is consistent with the preservation or environmental conservation; and the preservation of the relationship between the archeological site and its pieces via the site museum, which is the most appropriate use of the monument as indicated by the theory of objective restoration. This is an intervention of the archaeological area that by and large was respectful of the principles of contemporary scientific restoration.

\section{KEYWORDS}

Review of heritage, Bodega y Quadra house, intervention

(*) El artículo "Critica a la intervención en el yacimiento arqueológico de la casa Bodega y Quadra" fue elaborado a partir de un trabajo previo, titulado Comparación de la intervención realizada en la casa Bodega y Quadra, y el Teatro de Títeres Gadir, planteado en el curso Metodología de la intervención en el patrimonio inmueble (ciclo 2016-1), dictado por el MSc. Arq. José Hayakawa Casas en la Maestría de Gestión de Patrimonio Cultural de la Unidad de Posgrado de Ciencias Sociales de la Universidad Nacional Mayor de San Marcos.

$\left.{ }^{* *}\right)$ Licenciado en arqueología mediante la tesis Secuencia constructiva de las estructuras hidráulicas halladas en la primera cuadra de Jr. Cusco del Centro de Lima en el año 2012, bajo la asesoría del licenciado en arqueología Miguel Pazos Rivera; autor del libro Casa Hacienda Santiago de Punchauca; director del Proyecto de Monitoreo Arqueológico Rutas de Lima, tramo Panamericana Norte; y alumno de la Maestría de Gestión de Patrimonio Cultural de la Unidad de Posgrado de Ciencias Sociales de la Universidad Nacional Mayor de San Marcos. Contacto: arqrolandoarciga@hotmail.com

$\left.{ }^{(* * *}\right)$ El Centro Histórico de Lima se encuentra dentro de la lista de Patrimonio de la Humanidad de la UNESCO. Originalmente fue declarado el Conjunto Monumental de la Basílica de San Francisco y Convento en el año 1988; posteriormente, como extensión de este pronunciamiento, lo fue el Centro Histórico de Lima en 1991. Comprende gran parte del área fundacional, ocupada durante su primer siglo de existencia de Lima. 


\section{Conceptos, categorías y principios de la restauración}

Parte de la intervención realizada en el yacimiento arqueológico de la casa Bodega y Quadra fue una restauración. Al respecto, la Carta Internacional sobre la Conservación y la Restauración de Monumentos y de Conjuntos Histórico-artísticos de Venecia (1964) indica en el artículo 9 lo siguiente:

La restauración es una operación que debe tener un carácter excepcional. Tiene como fin conservar y revelar los valores estéticos e históricos del monumento y se fundamenta en el respeto a la esencia antigua y a los documentos auténticos. Su límite está allí donde comienza la hipótesis: en el plano de las reconstituciones basadas en conjeturas, todo trabajo de complemento reconocido como indispensable por razones estéticas o técnicas aflora de la composición arquitectónica y llevara la marca de nuestro tiempo. La restauración estará siempre precedida y acompañada de un estudio arqueológico e histórico del monumento. (p. 3)

El párrafo plantea que se debe respetar la esencia antigua del monumento, mantener su autenticidad; proceder con cautela referente a los materiales y técnicas a aplicar; hacer evidente el uso de materiales actuales; y realizar estudios históricos y arqueológicos previos a la restauración.

La restauración también puede presentar categorías. Para Salvador Muñoz Viñas existen tres: “Preservación, o conservación ambiental (o indirecta o periférica); conservación, o conservación directa; y restauración." (2003, pp. 23-24). La preservación, o conservación ambiental implica adecuar las condiciones ambientales o del entorno para que el bien se preserve. La conservación o conservación directa es la actividad que prepara el bien para que este sufra la menor cantidad de alteraciones interviniendo directamente en el. La restauración es la actividad que aspira a devolver al monumento sus características anteriores.

Por su parte, Giovanni Carbonara hace una relación de los principios de la restauración científica: "Distingüibilidad, reversibilidad, autenticidad, mínima intervención y compatibilidad" (1996, p. 16). La distingüibilidad de los materiales modernos en las restauraciones que ya había sido indicada en la Carta de Venecia, se refiere a que los agregados modernos deben poder ser fácilmente reconocidos. Además, la reversibilidad es un principio que indica que debe ser posible retirar los agregados modernos. El principio de autenticidad, también ya referido en la Carta de Venecia, se refiere a que cualquier elemento agregado en la intervención debe ser fácilmente distinguible sin que resulte violento o estridente. La idea de mínima intervención indica que esta debe limitarse a los casos en que es totalmente necesaria, para no alterar demasiado el monumento. Por último, la compatibilidad se refiere al uso de materiales que no alteren, dañen o provoquen alguna reacción adversa al monumento, por lo que es ideal el uso de elementos hechos con los mismos materiales que los originales.

Posteriormente a la restauración es frecuente que se le dé un nuevo uso al monumento intervenido; en muchos casos tal nuevo uso es la causa de la intervención. Sobre el uso que se le debe dar al monumento, Antoni Gonzáles Moreno-Navarro, en su trabajo sobre la restauración objetiva, menciona lo siguiente:

La restauración objetiva, por definición. Constituye un criterio esencial garantizar el uso del objeto, el monumento, un uso sensato, compatible con la permanencia de sus valores esenciales (Documentales, arquitectónicos y significativos). En primer lugar siempre que sea posible y éticamente conveniente, el uso primigenio, en cuanto este forme parte esencial del valor documental. Y si no fuera posible, el más adecuado para satisfacer el objetivo genérico de la restauración sin perjudicar el monumento. (2000, p. 115)

Así, plantea cómo debe escogerse el uso más adecuado para el monumento a intervenir, debido a que dependiendo de este se tendrán que realizar cambios en la arquitectura. 


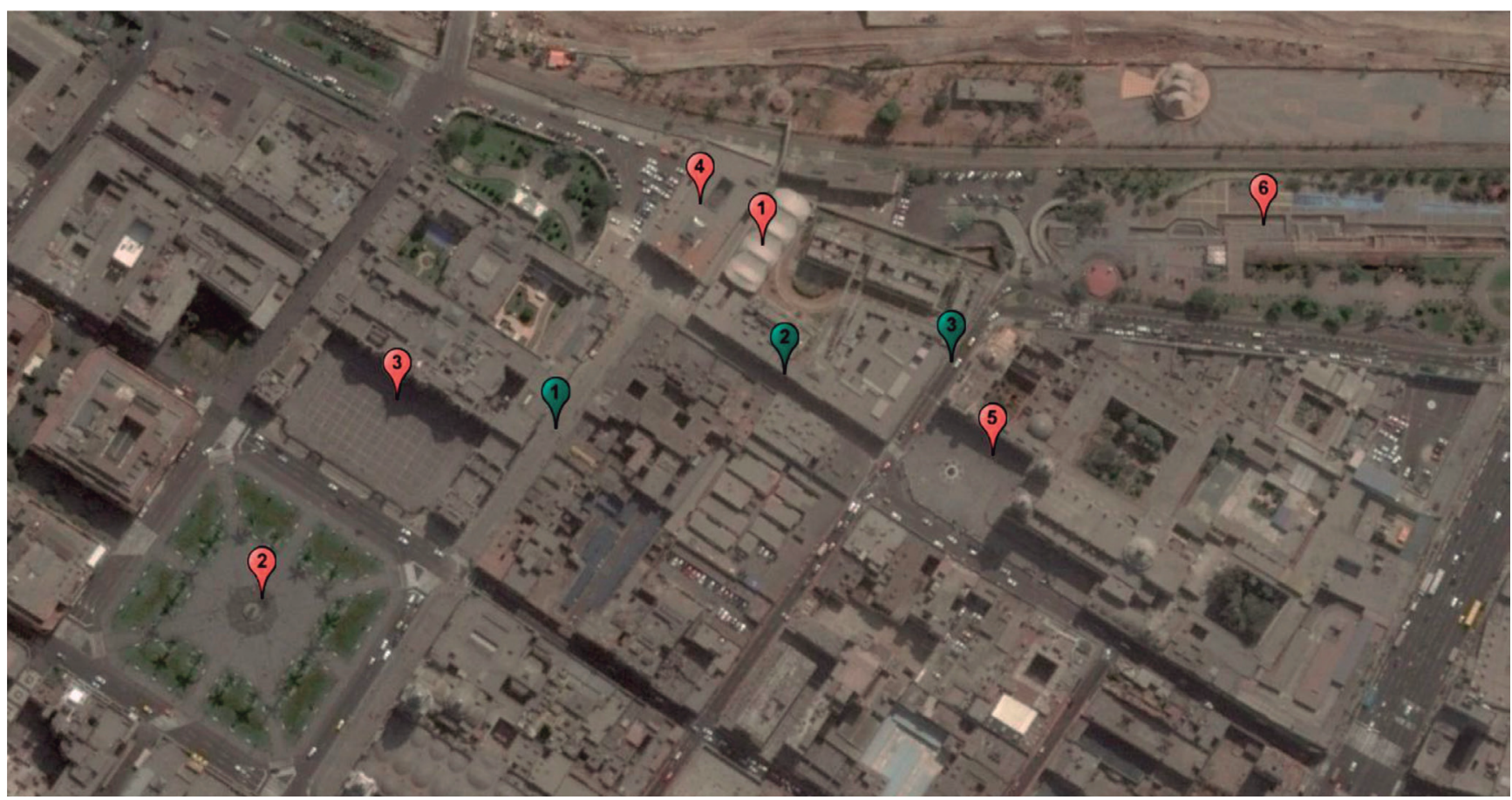

\section{Descripción del bien}

La casa Bodega y Quadra se encuentra ubicada en el Jr. Áncash № 209, 213 y 217, entre la Casa de la Literatura Peruana (Ex Estación de Tren Desamparados) ${ }^{1}$ y el Conjunto Monumental de San Francisco' ${ }^{2}$, en el Centro Histórico de Lima. En la actualidad es un museo de sitio que cuenta con un yacimiento arqueológico ubicado en la parte posterior. La casa y el yacimiento han atravesado un largo proceso de restauración y puesta en valor; la primera se ha convertido en un museo de sitio donde se exhiben las piezas halladas durante el proceso de excavación arqueológica (Figura 1).

Un historiador que investigó la historia de la casa y del dueño más célebre, Juan Francisco de la Bodega y Quadra, fue Teodoro Hampe Martínez, quien menciona que en el siglo XVI, sobre el terreno de la Casona Bodega y Quadra, se ubicó el rastro o la carnicería principal de Lima, así como también las primeras fundiciones. Tras ser un espacio público en un inicio, en el siglo XVII pasó a tener como propietario a la familia De la Cueva, que vendió una parte del mismo para construir la Iglesia de Los Desamparados ${ }^{3}$, mientras que el área restante se convirtió en una residencia. Posteriormente, en el siglo XVIII, esta sería adquirida por la familia Bodega y Quadra, de ascendencia vasca ${ }^{4}$, quienes tras el terremoto de 1746 construyeron una nueva casa en 1748 . La familia vivió ahí hasta el año 1864 (Hampe, 2008).

\footnotetext{
1. Es una antigua estación de trenes, del año 1912, que se encuentra al lado del Palacio de Gobierno. La actual estación es de estilo académico francés y fue construida en el lugar donde se encontraba la antigua estación del Ferrocarril Central. Comenzó a funcionar como Casa de la Literatura Peruana a partir del año 2009.

2. El Conjunto Monumental de la Basílica y Convento de San Francisco de Lima, también llamado San Francisco el Grande, se comenzó a construir en 1546

3. La Iglesia de Desamparados, construida en 1663 , se vio gravemente afectada por los terremotos del siglo XIX. Así, se construyó un nuevo templo en el año de 1898, el cual fue demolido en 1939

4. Los vascos son una población europea, principalmente asentada en el norte de España.
}

Figura 1. Con verde: 1. Cuadra $1 \mathrm{de} \mathrm{Jr.}$ Carabaya, 2. Cuadra 2 de Jr. Áncash, 3. Cuadra 1 de Jr. Lampa. Con rojo: 1. Casa Bodega y Quadra, 2. Plaza Mayor de Lima, 3. Palacio de Gobierno, 4. Casa de la Literatura Peruana 5. Conjunto monumental de San Francisco, 6. Parque de la Muralla

Fuente: Elaboración propia sobre la base de una imagen de Google Earth, 2016. 
A fines del siglo XVII y principios del siglo XVIII se realizaron planteamientos sobre el tratamiento de los desechos para usarlos para nivelar depresiones; es así que la Plataforma 02 (en esta se encuentra el yacimiento arqueológico, mientras que en la Plataforma 01 se ubica el museo) de la casa fue sepultada con tierra y objetos. Sobre tal proceso Miguel Fhon Bazán indica lo siguiente:

En el caso de la Plataforma 02, por encontrase sobre la ladera del rio recibió la acumulación de los rellenos constructivos de un periodo posterior al uso del espacio, con el fin de nivelar el área con el sector de ingreso, práctica que ya se venía realizando parcialmente desde fines del siglo XVII y durante el siglo XVIII, ocasionando el enterramiento de las estructuras virreinales allí existentes. En este nuevo terraplén adaptado sobre las estructuras virreinales sepultadas, se construyeron por superposición las estructuras republicanas usando materiales más livianos (como quincha y madera), formado una serie de recintos laterales unidos por un corredor central muy estrecho.... (2014, p. 124).

Sobre lo que pasó posteriormente con la casa, Teodoro Hampe (2008) menciona lo siguiente: al morir sin hijos Mariano de la Bodega y Quadra en el año de 1845, esta pasó a poder de Toribio Sanz en el año de 1864; la casa ya para esta época se encontraba deteriorada, pues durante la Guerra con Chile ${ }^{5}$ la familia Sanz se encontraba en París y había dejado en abandono el inmueble. En el año 1957 el consejo Provincial de Lima expropió el bien a los señores Suttor Sanz y Suttor Arrarte, a quienes se les pagó 1'600,000 soles.

Finalmente, en las últimas décadas del siglo XX, sobre el terreno y en la segunda cuadra de Jr. Áncash (antiguamente llamada Calle del Rastro) se construyeron casas muy precarias, las cuales se encontraban tugurizadas ${ }^{6}$. Según el trabajo del arquitecto Jorge Orrego Vargas (2009), del cual pudimos acceder a la copia existente en el área de Patrimonio Histórico del Ministerio de Cultura, hasta antes de la intervención la casa se encontraba en una situación precaria y la fachada del inmueble había sido modificada, pues se habían habilitado dos grandes portones a cada lado del ingreso principal. Además, el inmueble se encontraba en un grave nivel de deterioro: los techos, muros, balcones y pisos se encontraban en mal estado de conservación, y la parte posterior de la casa estaba conformada por habitaciones muy precarias. Cabe resaltar que todo el edificio se encontraba tugurizado.

Originalmente se planteó la recuperación de este espacio para incluirlo dentro del proyecto del Conjunto Habitacional la Muralla, pero en el año 2003, durante el proceso de remoción de tierra, tuvo lugar el hallazgo de estructuras de la época de la Colonia, por lo cual se sugirió la realización de un proyecto de arqueología, al cual se dio inicio en 2004.

En la parte posterior de la casa, en la zona donde se encontraban habitaciones precarias, en el subsuelo se halló una serie de restos de la época colonial, los cuales no se sabía que aún existían. Durante el proyecto arqueológico se pudo observar que el yacimiento arqueológico de Bodega y Quadra estaba comprendido por una serie de 23 recintos cuadrangulares, rectangulares e irregulares, todos construidos con adobe, ladrillo, piedra y canto rodado.

Los recintos con forma irregular ( 1,2 y 3$)$-los cuales forman un solo espacio que por motivos metodológicos de la excavación arqueológica fue separado- se encuentran ubicados al lado del tajamar. En el extremo Oeste del recinto se ubica un testigo de tierra dejado durante el proceso de excavación, y al Este, un arco.

\footnotetext{
5. Conflicto armado que se desarrolló entre los años 1879 y 1883.

6. Una o varias unidades de vivienda que no reúnen las condiciones básicas de habitabilidad por tener deficiencias en cuanto al área vital; servicios de agua, desagüe y energía eléctrica; iluminación y ventilación naturales; e, igualmente, por estar deterioradas y no contar con posibilidades de ampliación o de remodelación.
} 


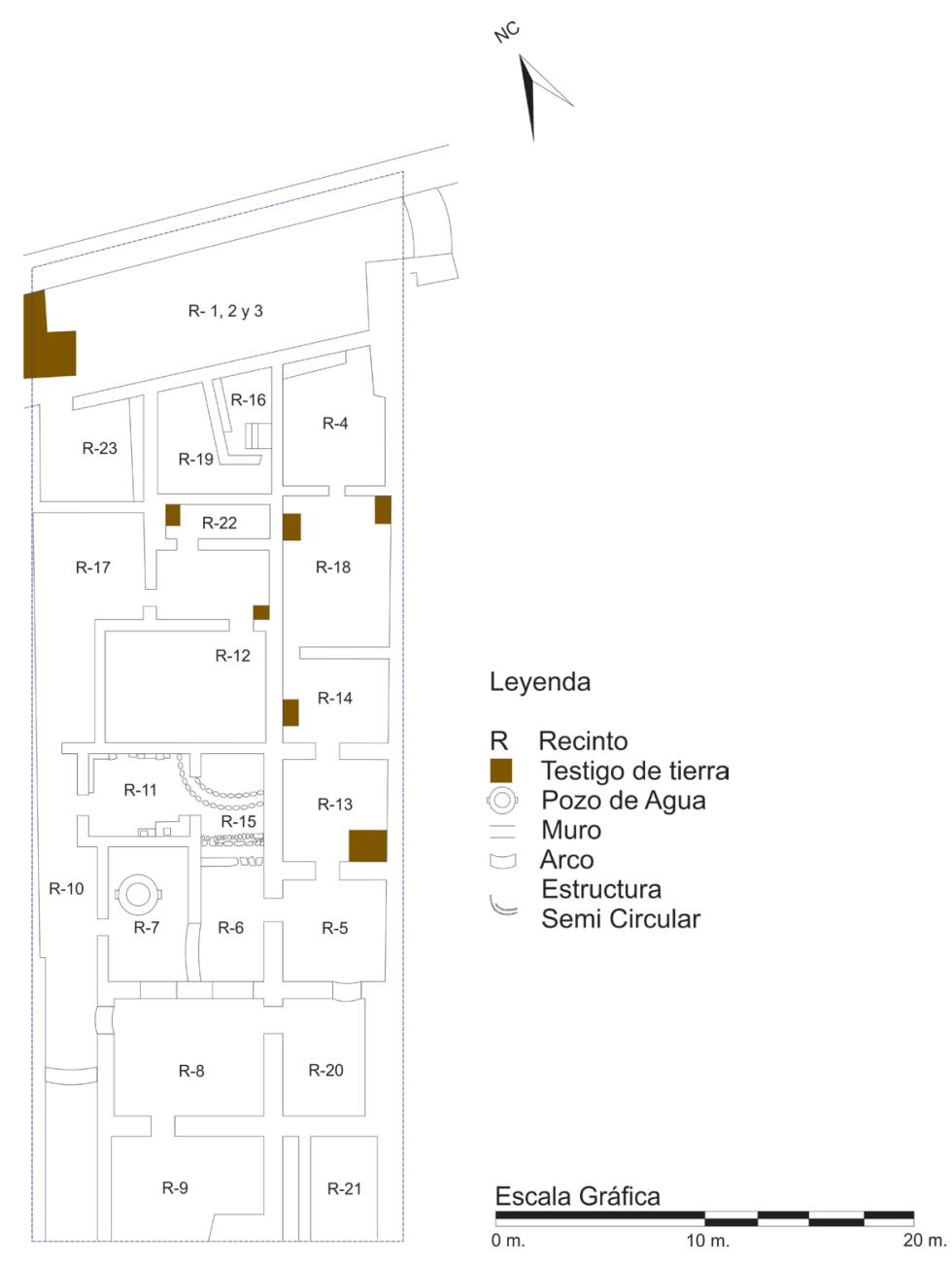

Figura 2. Plano del yacimiento arqueológico de Bodega y Quadra

Fuente: Elaboración propia sobre la base de un panel informativo del Museo del Sitio Bodega y Quadra, 2012.

En el recinto número 4, se instalaría la subida para los miradores 2 y 3, mientras que el recinto 9 fue soterrado para la construcción del mirador 1 y el 10 -ubicado en la parte Oeste del yacimiento- cumplía la función de pasadizo y presenta un piso empedrado. Además del arco presente entre el recinto 10 y el 8 , hay otro que se encuentra a pocos metros del ingreso al yacimiento. El recinto 12 -cuyo espacio está subdividido en dospresenta en el interior un testigo de tierra y cuenta con un piso empedrado, al igual que los recintos 17 y 23 ; el 16 y el 19 están debajo del mirador 2.

Los recintos de forma cuadrangular son el 5 -el cual tiene un arco en el acceso que intercomunica con el recinto 20-; el 13 -el cual posee en su interior botijas, un testigo de tierra y piso de adobe-; el 18 -donde se encontraba la antigua carnicería de la ciudad y se dejaron dos testigos de tierra-; el 20 -que cuenta con un arco en el acceso que lo intercomunica con el recinto $8-$ y el 22 -estrecho y con un testigo de tierra-.

Los recintos con forma rectangular son el 6 -con un arco grande en el acceso que lo intercomunica con el recinto 7-; el 7 -donde se ubica un pozo de agua-; y el 8, que presenta un arco en el acceso que lo intercomunica con el recinto 10. Todos los anteriores cuentan con piso empedrado. Además, están el recinto número 11 -donde se aprecian bases de columnas-; el 14 -donde se dejó un testigo de tierra-; el 15 -que presenta una serie de estructuras semicirculares-; y el 21 -soterrado para construir el mirador 1- (Figura 2). 
La casa Bodega y Quadra fue declarada Patrimonio Cultura de la Nación mediante la Resolución Directoral Nacional 1327/INC/2004 del Instituto Nacional de Cultura. La zona del yacimiento arqueológico comprende un área de $940.41 \mathrm{~m}^{2}$ y un permetro de $139.34 \mathrm{~m}$. La intervención con miras a su restauración y posterior puesta en valor fue decidida a través del acuerdo de consejo el 7 de Mayo de 2009, Memorando № 391-2009 GMM-MML, en el cual se firma un acuerdo entre la Municipalidad de Lima, la Agencia Española de Cooperación Internacional para el Desarrollo (AECID) y la Escuela Taller de Lima para la realización de proyectos piloto dentro del marco del "Plan estratégico de la recuperación del Centro Histórico de Lima 2006-2035". La intervención de restauración y puesta en valor fue ejecutada entre los años 2010 y 2012. Durante 2010 se comenzó a llevar a cabo los trabajos de consolidación y puesta en valor del yacimiento arqueológico como indica la memoria anual 2010 de la Empresa Municipal Inmobiliaria de Lima (EMILIMA): "El proyecto contempla la puesta en valor y consolidación del área arqueológica ubicada en la casa Bodega y Quadra..." (EMILIMA, 2010, p. 12). Durante el año siguiente, según la memoria anual de la empresa, se realizó las siguientes actividades: liberar elementos ajenos a la construcción y aquellos en mal estado de conservación, e intervención en los arcos y consolidaciones (EMILIMA, 2011). Para el año 2012 se colocó la pasarela, los miradores y la cobertura, y si bien se tenía planificado terminar la obra para el primer trimestre de 2013, esta se inauguró el 12 de noviembre de 2012, aunque quedaban pendientes trabajos menores en el museo, como indica la memoria anual de ese año de EMILIMA:

Se tiene previsto la culminación de la obra durante el primer trimestre del 2013, tratándose de arreglos menores en ciertas zonas del museo, no obstante, se realizó su inauguración en noviembre del 2012, al encontrarse en óptimas condiciones para la visita de público beneficiario. $(2012$, p. 52)

Cabe resaltar la buena decisión por parte de la gestión municipal de poner en valor Bodega y Quadra, convertirla en un museo de sitio con un yacimiento arqueológico, el único de este tipo dentro del centro histórico de la ciudad, que ahora es ahora un espacio cultural, educativo y de esparcimiento.

\section{La ubicación favorable de la casa Bodega y Quadra}

La ubicación de la casa Bodega y Quadra es estratégica: el proyecto no hubiera sido tan exitoso si se hubiera ubicado en otra zona del Centro Histórico, pues el entorno que la rodea es totalmente favorable: se trata de una zona concurrida, de fácil acceso, en buen estado de conservación, con muchos negocios de diferentes tipos, y espacios culturales y de esparcimiento. La casa se encuentra dentro del eje peatonal (conformado por la primera cuadra de Jr. Carabaya y la segunda de Jr. Áncash) que lleva desde la Plaza Mayor ${ }^{7}$ hasta el Complejo de la Basílica y Monasterio de San Francisco el Grande. Si uno sigue desde la Plaza Mayor de Lima hasta la primera cuadra de Jr. Carabaya, primero verá al lado izquierdo de la calle el Palacio de Gobierno; a la derecha derecho el Museo del Pisco ${ }^{8}$, una taberna que se especializa en la preparación de cocteles derivados de este aguardiente, local muy atractivo debido a que mantiene su aire antiguo a la vez que difunde la historia del producto; al lado se encuentra el Chocomuseo, un comercio dedicado a la venta de chocolates; siguiendo por la calle se podrá llega a la Casa de la Literatura Peruana (antiguamente Estación del Tren de Desamparados); en la esquina con la segunda cuadra del Jr. Áncash se

\footnotetext{
7. La Plaza Mayor o Plaza de Armas es el sitio fundacional de la ciudad de Lima. Es el espacio público más importante de la ciudad; a su alrededor se encuentran el Palacio de Gobierno, el Palacio Municipal, la Catedral y el Palacio Arzobispal.

8. El pisco es un aguardiente de uva que tiene su origen en el Perú a finales del siglo XVI. Los departamentos donde históricamente se ha producido la bebida son Lima, Ica, Arequipa, Moquegua y Tacna.
} 

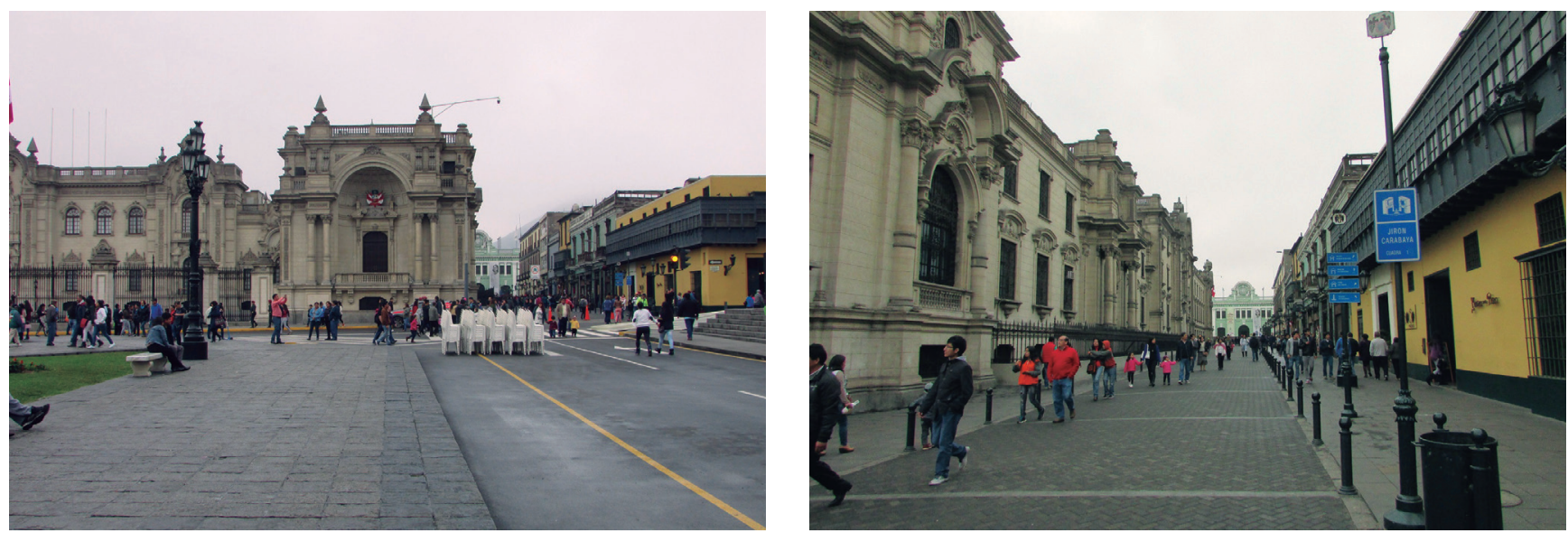

encuentra el histórico Bar Restaurante Cordano, el cual fue fundado en el año de 1905; y ya en la cuadra donde se encuentra Bodega y Quadra se puede apreciar una gran cantidad de tiendas que se dedican a la venta de souvenirs ${ }^{9}$ para los turistas (réplicas de cerámicas prehispánicas, tejidos, réplicas de pinturas de la escuela cuzqueña, licores, artesanías en general, etc). Además, debe resaltarse que las casonas en esta cuadra se encuentran intervenidas, lo cual ofrece un panorama muy diferente a otras calles donde los inmuebles están en malas condiciones de conservación. Más adelante se encuentra el Complejo Monumental de San Francisco, el cual es único en su tipo en esta parte del mundo, originalmente declarado como Patrimonio de la Humanidad por parte de la UNESCO ${ }^{10}$ en el año 1988. También cabe mencionar que cerca se encuentra el Parque de la Muralla ${ }^{11}$; este se encuentra a un lado de Jr. Amazonas, y se llega allí desde Bodega y Quadra transitando por Jr. Áncash y luego prosiguiendo por Jr. Lampa; la distancia es de 200 metros. En el Parque de la Muralla, de igual manera que en Bodega y Quadra, se puede apreciar restos de la antigua Lima Colonial, una sección de tajamar ${ }^{12}$ de la Muralla de Lima, y también existe un museo donde se exhibe algunas piezas coloniales y republicanas (Figuras 1, 3, 4, 5 y 6).

Cabe mencionar la buena condición de conservación que presenta actualmente la segunda cuadra de Jr. Áncash (antigua Calle del Rastro), compatible con el concepto de la preservación o conservación ambiental planteado por Salvador Muñoz, quien indica que "Preservación o conservación ambiental (o indirecta, o periférica), es la actividad que consiste en adecuar las condiciones ambientales en que se halla un bien para que este se mantenga en el estado presente" (2003, p. 23). Las casas que se encuentran en esta cuadra han sido restauradas y dejaron de estar tugurizadas; en el estado en que se encontraban anteriormente, causado por filtraciones de agua por tuberías en malas
Figura 3. Cuadra 1 de Jr. Carabaya desde la Plaza Mayor de Lima

Fuente: Archivo fotográfico personal Rolando Arciga, 2016.

Figura 4. Cuadra 1 de Jr. Carabaya con el remate visual de la Casa de la Literatura Peruana (Ex Estación de Tren de Desamparados)

Fuente: Archivo fotográfico personal Rolando Arciga, 2016

9. Los Suvenir son recuerdos, que se adquieren para poder revivir o recordar los viajes realizados en el pasado.

10. Organización de las Naciones Unidad para la Educación, la Ciencia y la Cultura. Fue fundada en 1945. Se dedica a orientar a los pueblos en pos de una gestión más eficaz de su propio desarrollo, a través de los recursos naturales y los valores culturales, y con la finalidad de modernizar y hacer progresar a las naciones del mundo, sin que por ello se pierdan la identidad y la diversidad cultural.

11. Fueron fortificaciones construidas entre los años 1684 al 1687, principalmente con muros y bastiones, cuya finalidad era la defensa de Lima ante un ataque. La muralla estuvo ubicada entre las actuales avenidas Alfonso Ugarte, Paseo Colón y Grau, y la margen izquierda del rio Rímac. Fue demolida en 1868 para comenzar la expansión de la ciudad al sur.

12. Los tajamares son pequeños diques que se colocan cerca de los ríos para evitar inundaciones durante las crecidas de estos. 

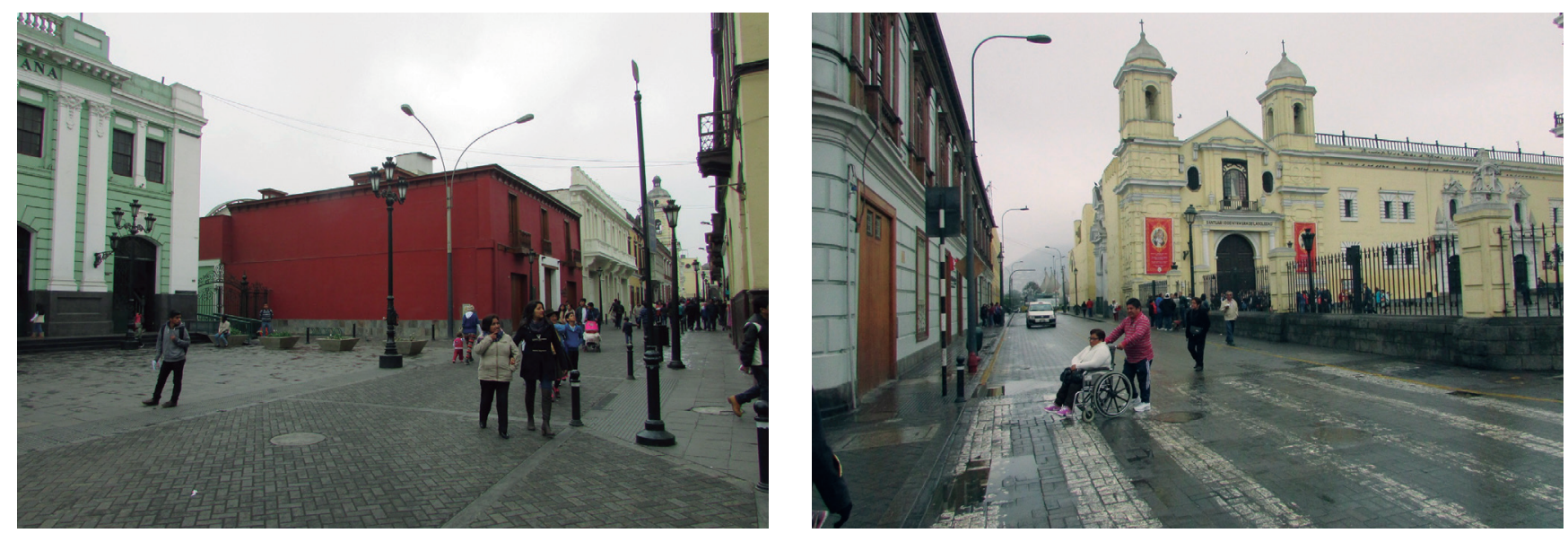

Figura 5. Cuadra 2 de Jr. Áncash (esquina de Palacio de Gobierno), con el Museo de Sitio Bodega y Quadra; y, al fondo, la torre de la Basílica de San Francisco

Fuente: Archivo fotográfico personal Rolando Arciga, 2016.

Figura 6. Cuadra 1 de Jr. Lampa; con la Capilla de Nuestra Señora de la Soledad y parte del Convento de San Francisco. Al fondo se encuentra el Parque de la Muralla

Fuente: Archivo fotográfico personal Rolando Arciga, 2016. condiciones y desplomes de parte de las estructuras por falta de intervención, hubieran significado un entorno adverso para la casa Bodega y Quadra.

\section{La preservación del lazo entre el yacimiento y sus piezas a través del Mu- seo de Sitio}

En 1982 el Consejo Internacional de Museos (ICOM) publicó un informe sobre los museos de sitio, donde estos se definen como "un museo concebido y organizado para proteger un patrimonio natural y cultural, mueble e inmueble, conservado en su lugar de origen, allí donde este patrimonio ha sido creado o descubierto". En 1983 la catorce asamblea general del ICOM, que se celebró en Londres el 1 y 2 de agosto, se incluyó en la lista a los sitios arqueológicos e históricos.

Otra definición de museo de sitio, planteada por Francisca Hernández Hernández, es la siguiente:

Esta tipología de museos se explica dentro de la concepción de la museología como ciencia del patrimonio. Hoy estamos asistiendo a un fenómeno mundial de la puesta en valor del patrimonio cuyo objetivo final es la conservación y presentación in situ del patrimonio cultural y natural para que pueda ser comprendido y disfrutado por un público cada día más amplio. Son exposiciones muy atractivas que relacionan los sitios patrimoniales con su entorno. $(2007$, p. 6)

El museo de sitio busca, entonces, la preservación con una coherencia científica que no separe las evidencias de su entorno; este mantiene el lazo que existe entre la pieza y el yacimiento, no como aquellos que exhiben piezas en muchos casos descontextualizadas, donde no se sabe exactamente de qué sitio son, o de qué parte del sitio provienen, ni se manifiesta su relación con otras piezas halladas.

La concepción de la casa Bodega y Quadra como un museo de sitio fue muy acertada, pues así los visitantes pueden, en primer lugar, apreciar las piezas en el museo, y conocer la historia de la casa y la ciudad de Lima; y, luego, dirigirse a la zona arqueológica y apreciar de dónde fueron sacadas las piezas; es así como el lazo entre yacimiento y piezas no se ha roto al ser trasladadas estas a otro lugar para su almacenaje o exhibición (Figura 7).

Las piezas del yacimiento son mostradas en el museo siguiendo un ordenamiento cronológico y temático, dispuestas en ocho salas. La primera sala aborda la ocupación prehispánica del valle (puede verse fragmentos de cerámica de las Culturas inca, chancay, ichma y costa norte) y los primeros años de la fundación de la ciudad hasta finales del siglo XVI (con la excepción de un batán del siglo XVI al XVIII). En la segunda 


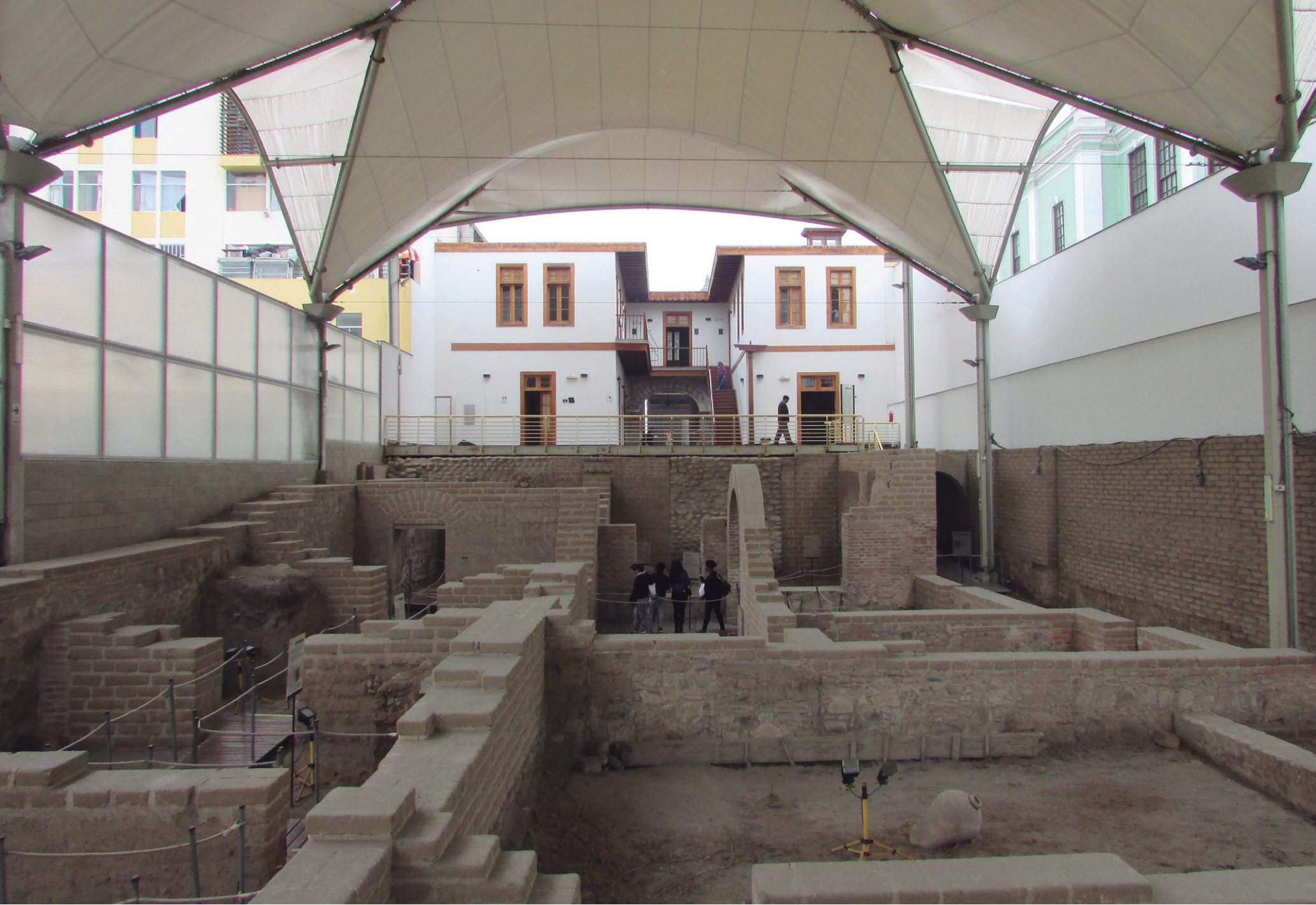

sala se puede apreciar vajilla de cerámica vidriada ${ }^{13}$ y azulejos ${ }^{14}$ de los siglos XVII al XVIII. La tercera sala muestra porcelana ${ }^{15}$ cchina del siglo, traída a Lima a través de la ruta española de comercio a Filipinas ${ }^{16}$; objetos religiosos y cerámica vidriada del siglo, todos objetos del período comprendido entre los siglos XVII y XVIII. En la cuarta sala se aprecian objetos relacionadas al comercio, como las botijas de interior vidriado del siglo XVIII que servían para el transporte de productos. La quinta sala reúne mayólica ${ }^{17}$ panameña y otros tipos de mayólica del siglo XVII al XVIII, así como objetos empleados para su producción. En la sexta sala se exponen objetos de higiene pública y de cultura material del siglo XIX. En la séptima se muestra objetos relacionados a la moda y el consumo de los siglos XIX y XX. Finalmente, en la octava sala están expuestas fotos del proceso de excavación, restauración e implementación del museo. También se exhibe
Figura 7. Foto tomada desde el segundo mirador; se aprecia el yacimiento arqueológico y al fondo el Museo de sitio

Fuente: Archivo fotográfico personal Rolando Arciga, 2016.

13. Se obtiene al cubrir la cerámica con óxido de plomo y otros óxidos; y cocerla a temperaturas superiores a $\operatorname{los} 750^{\circ} \mathrm{C}$

14. Es una pieza de cerámica muy similar a las baldosas, con una de las caras vidriadas y diseños con diferentes tonos cromáticos obtenidos a través de óxidos de metales. El azulejo se ha usado como elemento decorativo en casas, palacios, iglesias y conventos.

15. La porcelana es un material cerámico originalmente producido en la china desde el siglo VII o VIII, que se caracteriza por ser blanco, compacto, frágil, duro, traslúcido, impermeable, resonante, de baja elasticidad, y altamente resistente al ataque químico y al choque térmico.

16. La ruta, inaugurada en el año de 1565, tenía como origen Manila, en Filipinas, y pasaba por el puerto de Acapulco en México, donde la carga era embarcada en el puerto de Veracruz rumbo a España. También desde Acapulco eran embarcados los productos a otros puertos americanos.

17. Decoración en cerámica hecha con óxido de plomo opacificado con estaño. Posteriormente se decora los diversos motivos con óxidos sobre la anterior base. hornea a temperaturas entre los 980 y $1050^{\circ} \mathrm{C}$. 


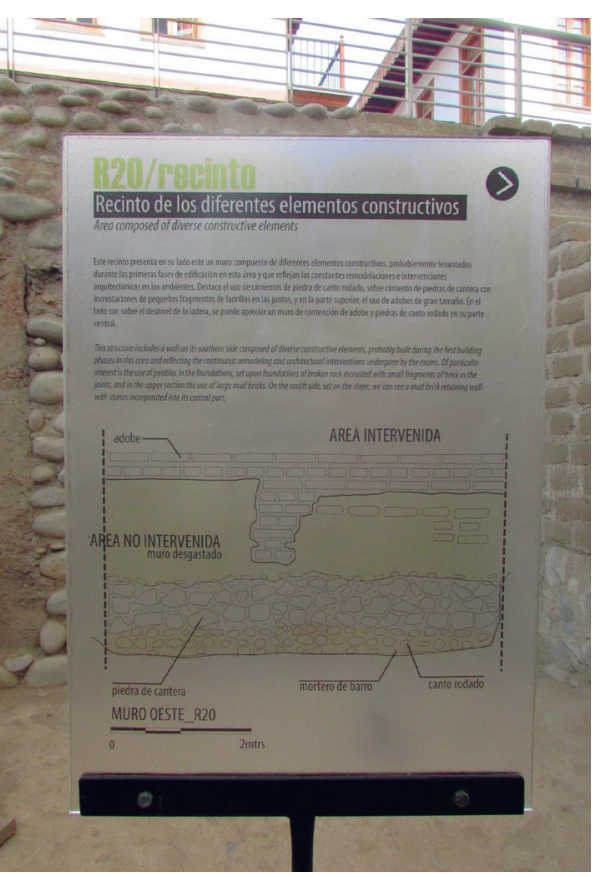

Figura 8. Panel informativo del recinto 8 , explicando que parte no ha sido intervenida (original) y cuál sí (agregada en el proceso de restauración)

Fuente: Archivo fotográfico personal Rolando Arciga, 2016. en una pantalla un video de la vida de Juan Francisco de la Bodega y Quadra, según Teodoro Hampe Martínez: nació en la Ciudad de Lima en 1744 y murió en la Ciudad de México en 1794; fue un oficial naval criollo descubridor de la Isla de Vancouver (Canadá); y heredó la casa de su padre, Thomas de la Bodega y Quadra (Hampe, 2006, p. 3435). Cabe destacar que en las salas del museo, al lado de la exhibición de las piezas, se ubican con intención explicativa planos e ilustraciones relacionadas. Una carencia que resalta es que aún no se cuenta con publicaciones hechas por el propio museo sobre el proceso de la excavación, la restauración e implementación del museo, o investigaciones posteriores sobre el material.

\section{La intervención en el yacimiento}

La intervención realizada en la casa Bodega y Cuadra está relacionada al nuevo uso o función que tendría el yacimiento arqueológico. Podemos apreciar que esta sigue el principio de la restauración objetiva de Antoni Gonzáles Moreno-Navarro, quien indica que "La restauración objetiva es el uso más adecuado que se le puede dar al monumento, siendo el ideal el que tenía antes de la intervención y de no poder ser así, uno que no perjudique su integridad" (2000, p. 115). En el caso de Bodega y Quadra no se le pudo dar el uso original, pero se le dio el de museo de sitio, el cual implicaba una adecuación orientada exclusivamente para exhibirlo a los visitantes; otro uso hubiera obligado un mayor nivel de intervención. Es así que la intervención se puede dividir en dos etapas: la primera, la restauración de la arquitectura del yacimiento; y la segunda, que consistió en la implementación para recibir a los visitantes.

En cuanto a la restauración arquitectónica en el yacimiento de Bodega y Quadra, según Jorge A. Orrego Vargas (2009) se aplicaron las siguientes categorías de intervención: intervención por consolidación, por restitución y por liberación. Sobre las especificaciones de lo que significó para el proyecto la intervención por consolidación, Orrego indica lo siguiente:

Categoría referida al proceso de recuperación de los elementos componentes de un edificio monumental, capaz de devolver las condiciones físicas y químicas que permitan su permanencia en el tiempo, con las condiciones técnicas propias y que dependen del propio material. El uso de tecnología apropiada y de última generación es recomendable, siempre y cuando no tenga un impacto negativo en la apariencia formal del componente: mejoramiento de las condiciones estructurales y de la estabilidad del edificio; construcción de cimiento, sobre cimiento de piedra; reforzamiento estructural de muro de adobe y ladrillo.... (2009, p. 456).

En lo que respecta a la intervención por restitución, Orrego menciona que se trata de una "Categoría que se refiere a la recuperación de elementos y componentes de cuya existencia pasada se esté seguro...." (2009, p. 456). Finalmente, sobre la categoría de intervención por liberación, afirma que consiste en una "Categoría que considera el retiro, demolición o desmontaje de elementos extraños al contexto del monumento, y cuya presencia distorsiona el mensaje implícito de la edificación, o que su presencia contribuye en su deterioro..." (2009, p. 456).

Al evaluar la intervención realizada en la casa Bodega y Quadra según los principios de la restauración científica de Giovanni Carbonara, "Distingüibilidad, reversibilidad, autenticidad, mínima intervención y compatibilidad" (1996, p. 16), se puede realizar una serie de afirmaciones.

La distingüibilidad se define como "La distingüibilidad entre las integraciones y las partes originales para no falsear la lectura del Texto Histórico y garantizar, en cambio, una interpretación limpia y concreta" (Carbonara, 1996, p. 16). En algunos proyectos de restauración se suele marcar los adobes añadidos indicando el año o colocando alguna otra clave para indicar que estos son modernos, que fueron agregados por los restauradores; en otros casos se utiliza un material diferente (por ejemplo, si el material 

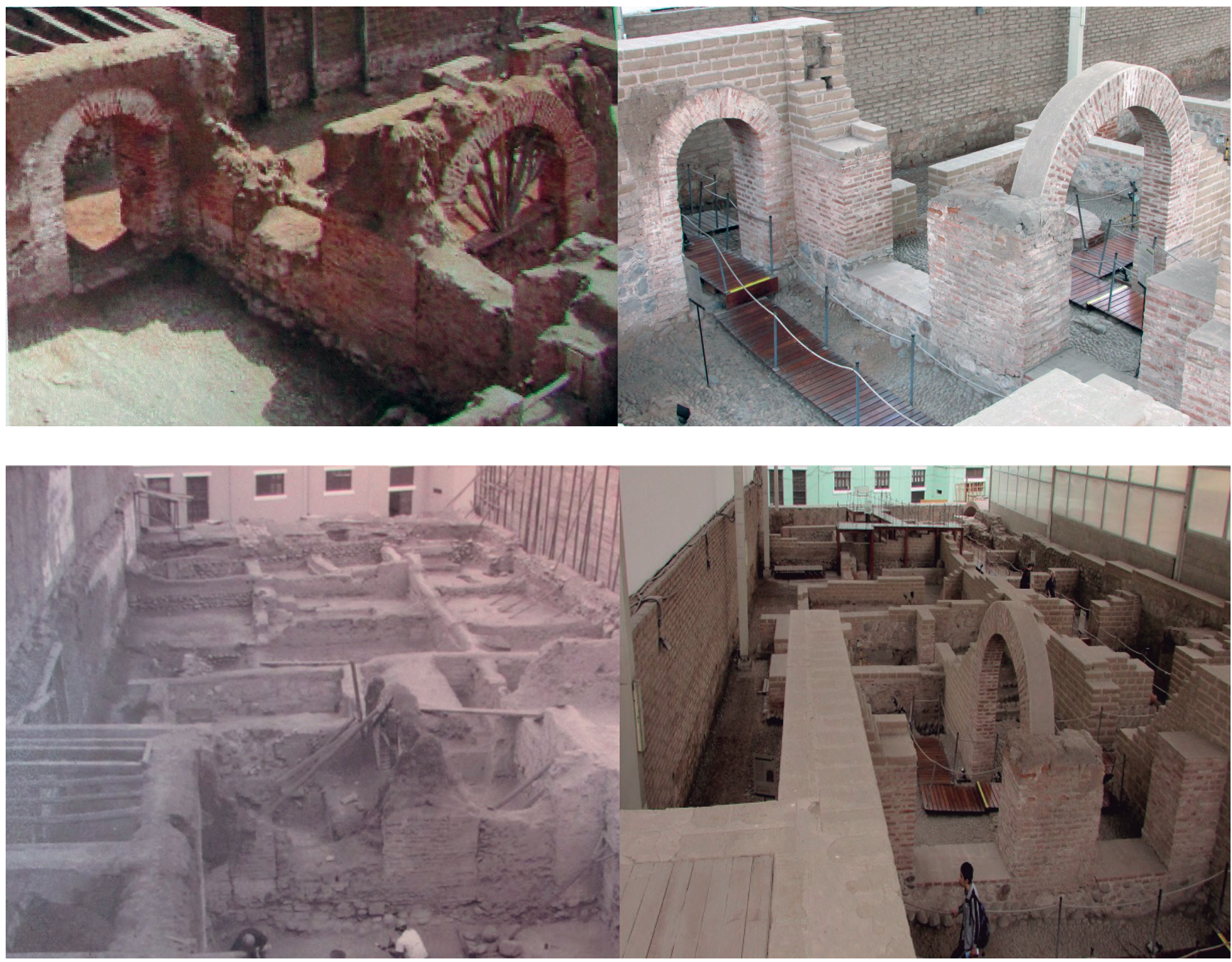

original es adobe se emplea ladrillo), pero ello entra en conflicto con el principio de compatibilidad. En el caso de Bodega y Quadra se decidió usar los mismos materiales utilizados en la construcción original, ya que si se pusiese enlucido a los adobes ello afectaría la estética del muro; sin embargo, tal decisión no resuelve el problema de cómo se diferencian los añadidos de los antiguos. Así, se optó por colocar paneles en cada sección, donde se indica mediante gráficos hasta qué hileras se trata del muro original y cuáles se colocaron durante el proceso de restauración (agregados modernos). Esta solución fue muy práctica, y además brinda la posibilidad al visitante de conocer más datos sobre el proceso de intervención en el inmueble (Figura 8).

La reversibilidad, implica “La reversibilidad de la intervención de restauración: se debe prever y no excluir la posibilidad de futuras intervenciones de corrección o rectificación, sin perjudicar por esto a la obra...." (Carbonara, 1996, p. 16). También este criterio se tomó en cuenta en la intervención realizada en la casa Bodega y Quadra: tanto los adobes como la argamasa son fáciles de retirar de la arquitectura antigua. Esta posibilidad es fundamental, debido a que futuras investigaciones podrían demostrar que la forma o altura del área agregada obtenida tras la restauración no es la correspondiente históricamente, y demandar una modificación.
Figura 9. Yacimiento arqueológico: a la izquierda, antes de la intervención; a la derecha, después de esta Fuente: Antes de la intervención, tomada de la octava sala del Museo de Bodega y Quadra, 2010. Después de la intervención, del archivo fotográfico personal Rolando Arciga, 2016.

Figura 10. Arco que se encuentra entre los recintos 8 y 10, y arco ubicado entre los recintos 6 y 7. A la izquierda, antes de la intervención; a la derecha, después de esta

Fuente: Antes de la intervención, tomada de la octava sala del Museo de Bodega y Quadra, 2010. Después de la intervención, del archivo fotográfico personal Rolando Arciga, 2016 
La autenticidad se refiere a"la autenticad expresiva: cualquier elemento que se agregue debe ser un testimonio inconfundible de nuestro tiempo, sin que su acercamiento a la obra resulte estridente o violento" (Carbonara, 1996, p. 16). Este principio está muy relacionado con el anterior, la distingüibilidad, pero también recalca el hecho que los elementos modernos deben mantener la estética de la parte antigua. Sobre este punto en Bodega y Quadra se ha colocado agregados modernos de la misma dimensión, técnica y semejante color de los antiguos; pueden distinguirse gracias a los paneles informativos, los cuales ilustran desde qué hilera de aparejo se trata de elementos modernos.

El principio de mínima intervención requiere "limitarse a intervenir solo cuando resulte indispensable para la conservación, alterando lo menos posible las prexistencias..." (Carbonara, 1996, p. 16). Este se ha seguido en la restauración, pues se mantuvo la esencia de yacimiento arqueológico de Bodega y Quadra; solo se retiró, como menciona Orrego, aquellos elementos ajenos al monumento y aquellos que se encontraban en estado de deterioro para reemplazados por otros modernos (Figuras 9 y 10). Por otro lado, entre el yacimiento de Bodega y Quadra, y la Casa de la Literatura Peruana (ex Estación de Tren Desamparados), se encontraba un muro de separación que debido a la excavación arqueológica quedó suspendido a varios metros del nuevo nivel del suelo, con lo que era inminente su colapso. Ante tal hecho se decidió demolerlo y en su lugar poner muros de drywall. La referencia de esta demolición se encuentra en la memoria anual de EMILIMA del año 2012: "Cerramiento hacia la Casa de Literatura Peruana, correspondiendo a la construcción de muros de drywall, muro que se realizó sobre el muro de concreto, y que reemplazó al muro que se había demolido" (p. 50). Sobre la colocación del nuevo muro, este fue puesto afectar al yacimiento arqueológico que se encontraba metros más abajo.

La compatibilidad es aquella que debe darse "entre los materiales originales y los empleados en la intervención, teniendo que verificarse sobre todo en el caso de emplear materiales modernos, de producción industrial o sintético..." (Carbonara, 1996, p. 16). En la intervención en los recintos se usó adobe, ladrillo, argamasa de cal y argamasa de barro, los materiales originales y, por lo tanto, compatibles.

La intervención de implementación para el ingreso de visitantes a la zona del yacimiento arqueológico incluyó la colocación de una pasarela por el yacimiento, tres miradores conectados a través de la pasarela, una cubierta, paneles informativos y otros elementos (maniquíes y réplicas de botijas).

La colocación de la pasarela para poder ingresar a la zona del yacimiento arqueológico desde el área en donde se encuentra el museo fue una decisión correcta. Debido a que los visitantes no pueden pisar el suelo arqueológico de la excavación, una opción que suele emplearse es la realización de un sendero señalizado preparado con tierra o piedras. Esta hubiera sido una solución muy simple, pero aun quedaría el problema de que la casa y el yacimiento no se encuentra al mismo nivel (la zona arqueológica está a 4 metros por debajo del nivel de la casa). Así, la solución fue la construcción de una pasarela que inicia como una escalera que baja hasta el nivel del yacimiento y prosigue a lo largo de un recorrido por los recintos hasta la zona cercana al tajamar del río. En ese punto se eleva y se conecta con dos miradores que sirven para poder apreciar las estructuras desde un punto alto. Así lo describe el informe anual de EMILIMA de 2012: "pasarela en el área arqueológica, trabajos que se han realizado para permitir el recorrido de los visitantes, conformado por estructuras de madera con barandales de tubo metálico y driza...." (p. 50). También cabe resaltar que por sus características es fácil sacar, ampliar o reducir el circuito compuesto por la pasarela, por lo que se está respetando el principio de reversibilidad. En cuanto a la mínima intervención, esta también se ha dado, pues la colocación de la pasarela no necesitó la construcción de columnas. El circuito que realiza la pasarela es el siguiente: se ingresa por el recinto 10, luego se prosigue a los recintos 8 y 20, posteriormente al 5, despúes a los recintos 6 y 7 (donde 


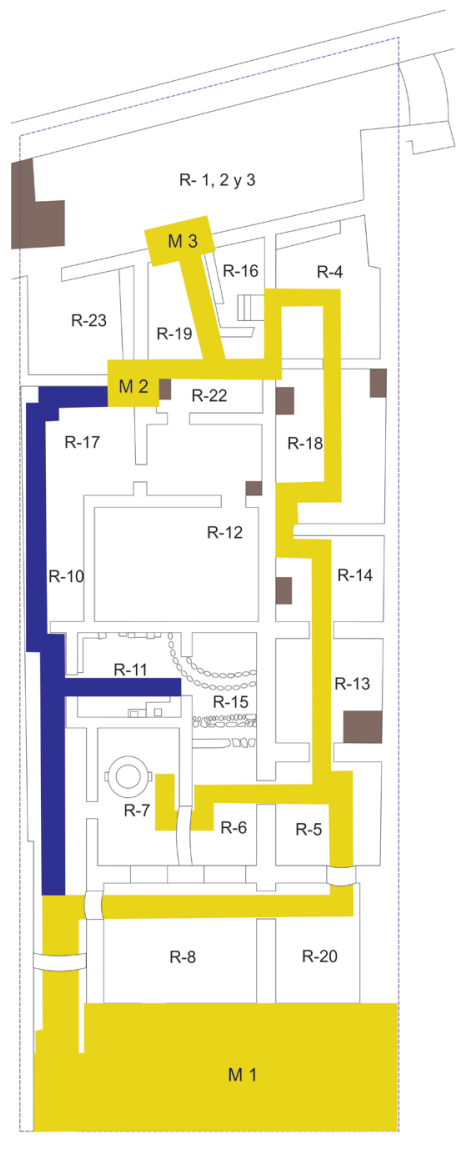

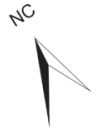

Leyenda

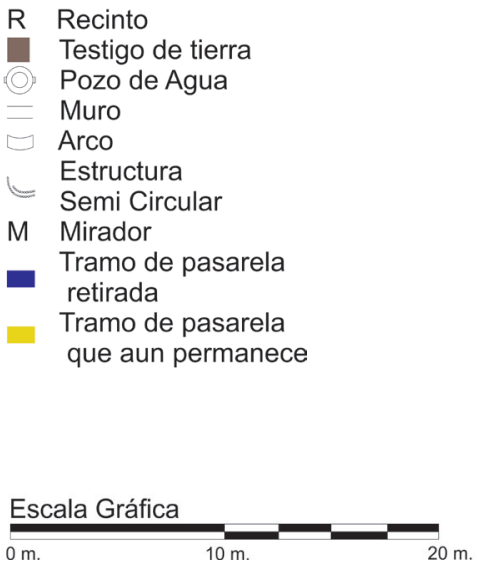

Figura 11. Plano del circuito turístico del yacimiento arqueológico de Bodega y Quadra

Fuente: Elaboración propia sobre la base del plano expuesto en panel informativo del Museo del Sitio Bodega y Quadra, 2012.

se encuentra el pozo), y, usando como regreso la misma ruta, se vuelve al recinto 5. Desde allí se reanuda el recorrido por los recintos 13 (Recinto de las Botijas), 14 y 18 (Carnicería); y se continúa por el recinto 4, donde la pasarela se eleva para conectarse con los miradores 2 y 3, desde los cuales se puede apreciar los recintos 1, 2, 3, 16, 19, 22 y 23 . Originalmente la ruta de la pasarela incluía mayor cantidad de recintos (incluía un retorno por los recintos 10 y 17), pero hace algún tiempo se ha reducido, lo cual provoca desorden, pues se cruzan en el mismo camino los visitantes que inician su recorrido con los que ya lo terminaron, lo cual genera incomodidad cuando hay muchas personas, ya que la pasarela no es muy ancha. Además de la reincorporación del tramo de pasarela retirado, debería plantearse colocar otras secciones en los recintos que nunca han formado parte del circuito, como el recinto 12, 23 y aquellos donde se ubica el tajamar (1, 2 y 3) (Figura 11 y 12).

Sobre la colocación de los tres miradores es necesario hacer algunas precisiones. La construcción del primer mirador, ubicado entre el museo y el yacimiento, requirió tapar los recintos 9 y 21, decisión que puede ser cuestionada por algunos, pero debe tenerse en cuenta que gracias a ello se pudo ganar un espacio que no solo ha tenido la función de mirador, sino que ha servido también como escenario de eventos académicos y culturales. Sobre el primer mirador EMILIMA, en su memoria anual de 2012, indica lo siguiente: "plataforma mirador, trabajos que han comprendido hacer el piso de la pla- 
devenir Vol. 3, №6, JULIO- DICIEMBRE 2016, pP. 31-48 - Estudios I ISSN 2312-7570

UnIVERSIDAD NACIONAL DE INGENIERÍA, LIMA
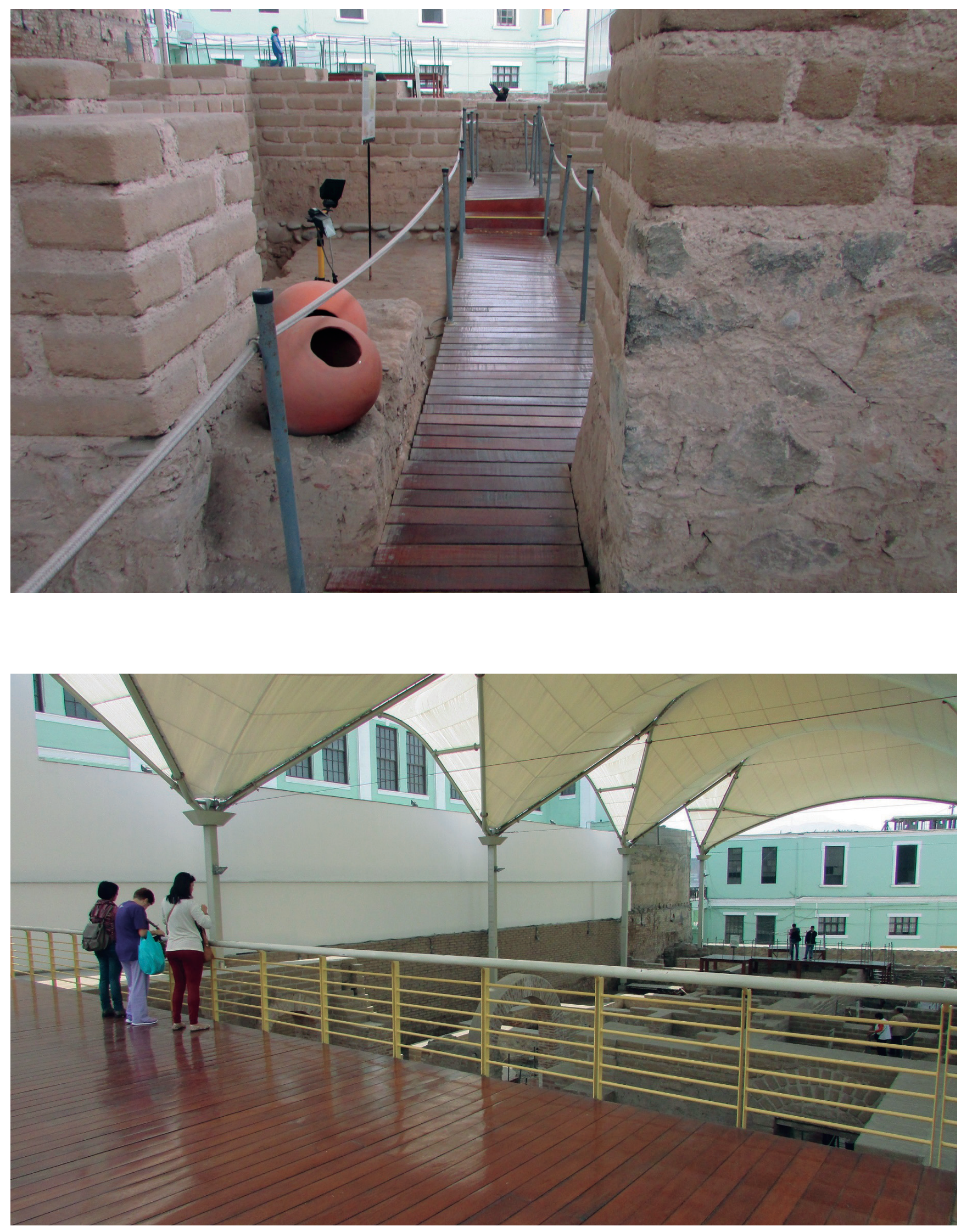


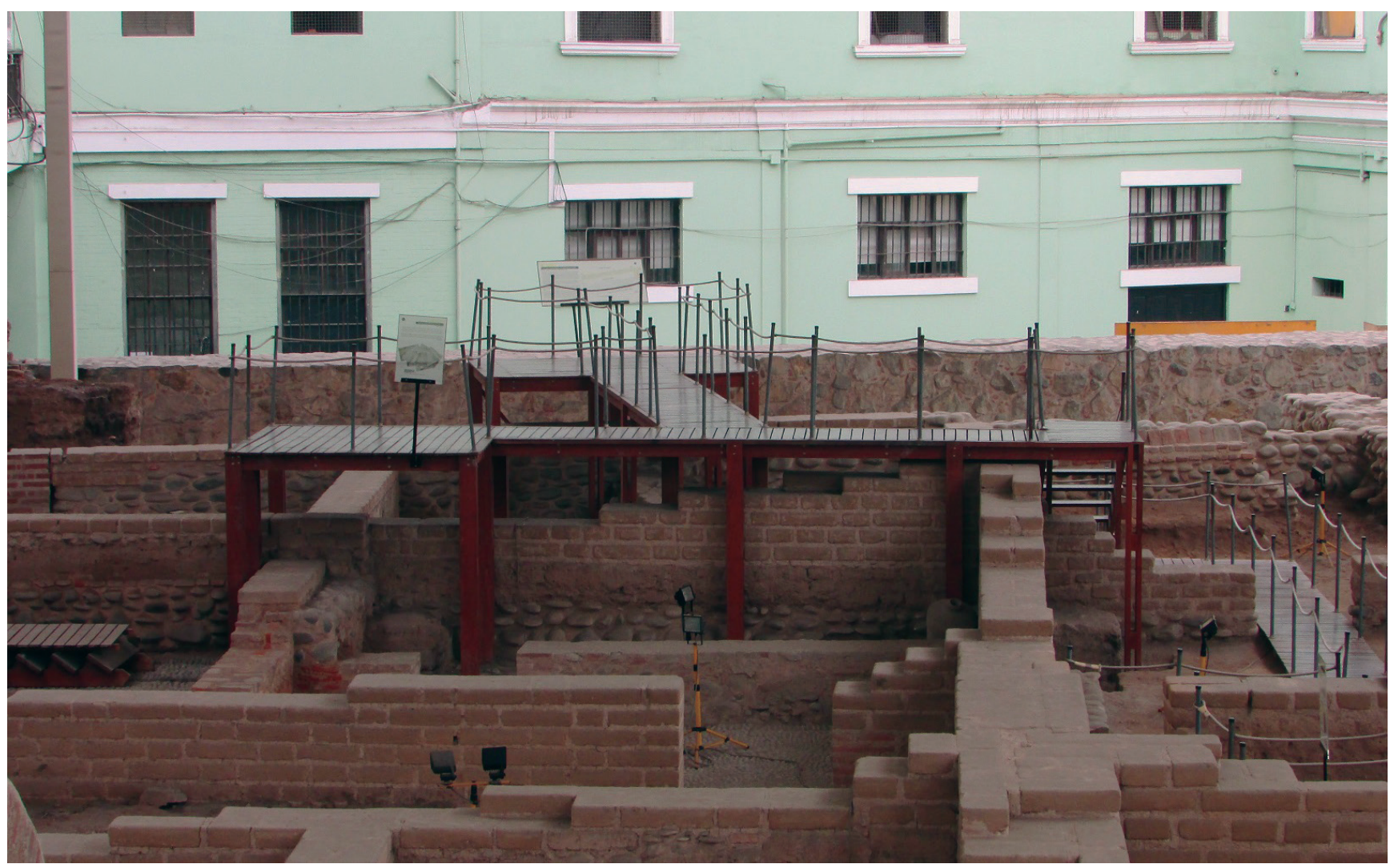

taforma del mirador de madera machihembrada sobre vigas metálicas, construcción de barandas y de la escalera de acceso al área arqueológica" (p. 50). El segundo mirador se encuentra entre los recintos 22, 17, 23 y 19; la decisión de colocarlo en ese punto es muy acertada, pues en ese caso no se sacrificó la visión de ninguno de los recintos, sino que se colocó entre recintos contiguos de forma que solo oculta de la vista una porción de estos y permite la visualización del resto. Además, a nivel del suelo aún se puede ver el espacio tapado por el mirador, cosa que no ocurre con el primero. En el caso del tercer mirador, este, al igual que el segundo, no oculta totalmente ningún recinto: se encuentra entre los recintos 16,19 y los del tajamar (1,2 y 3). Además, la estructura que lo soporta no oculta la visualización de los recintos a nivel del piso (Figuras 13 y 14).

La cubierta colocada cubre toda el área del yacimiento y se encuentra muchos metros por encima de esta. Así, cumple la función de proteger las evidencias de los efectos adversos del clima, y a la vez permite el ingreso de la luz solar y la ventilación. También cabe mencionar que la altura a la cual se encuentra permite una mejor visualización desde los tres miradores que hay en el yacimiento. EMILIMA describe así los trabajos de la colocación de la cobertura en su memoria anual del año 2012:"Comprende 10 columnas rectangulares de acero con sus respectivas zapatas y pedestales, 5 vigas reticulares de arriostre de acero, las que forman 4 módulos, y la cubierta de una malla de poliéster...." (p. 51). Se podría hacer una observación a respecto del diseño, que pudo haber sido más sobrio sin que deje de cumplir su función. Para la colocación de la cubierta se tuvo que construir columnas: las que se encuentran al Oeste están puestas dentro del yacimiento arqueológico, mientras que la del Este se encuentran fuera. Al evaluar esta intervención tomando en cuenta los principios de restauración, se puede afirmar que no se ha cumplido totalmente con el principio de mínima intervención, pues durante la
Figura 12. Pasarela que se encuentra en el recinto 13

Fuente: Archivo fotográfico personal Rolando Arciga, 2016.

Figura 13. Vista parcial del primer mirador

Fuente: Archivo fotográfico personal Rolando Arciga, 2016

Figura 14. Segundo y tercer miradorFuente: Archivo fotográfico personal Rolando Arciga, 2016 
devenir Vol. 3, Nº, JULIO-DICIEMBRE 2016, PP. 31-48 - EstudIOS I ISSN 2312-7570

UNIVERSIDAD NACIONAL DE INGENIERÍA, LIMA

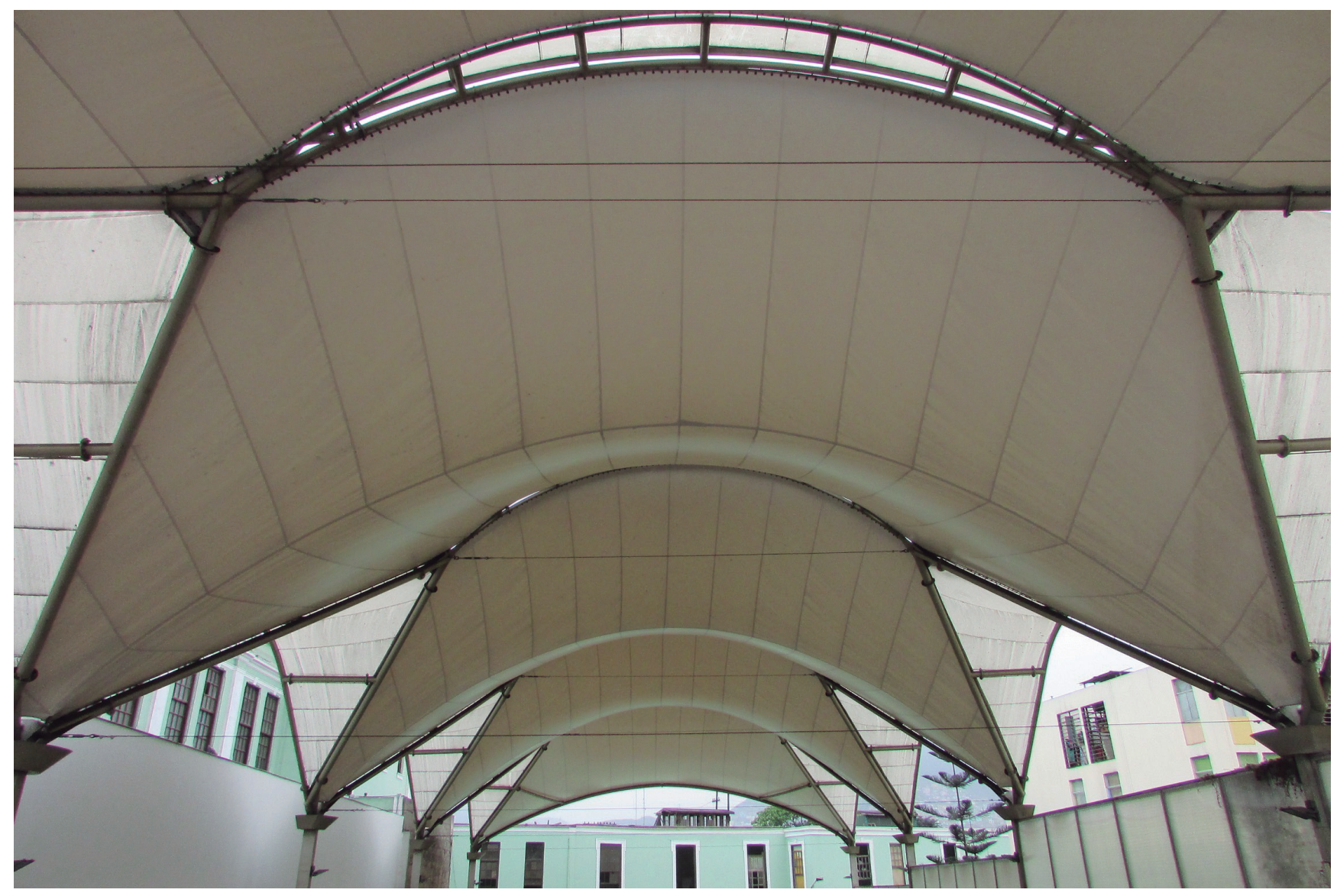

Figura 15. Cobertura del yacimiento arqueológico

Fuente: Archivo fotográfico personal Rolando Arciga, 2016.

Figura 16. Columna que sostiene la cobertura del yacimiento arqueológico

Fuente: Archivo fotográfico personal Rolando Arciga, 2016.

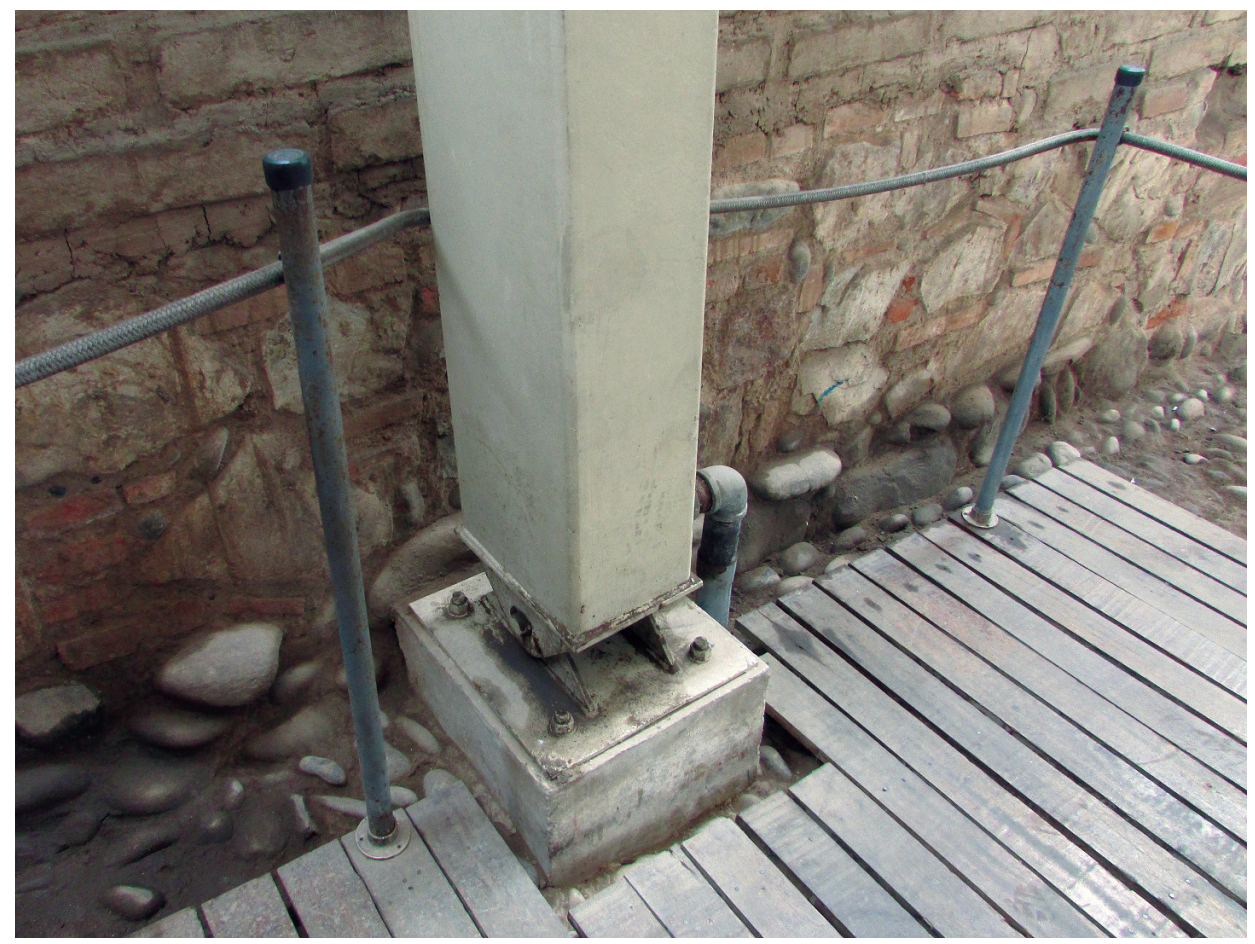


colocación de las columnas del lado Oeste hubo una pequeña afectación; además, en cuanto a la reversibilidad la cubierta, estas pueden ser retiradas pero, en el caso de las columnas del lado Oeste, no sin generar una afectación más (Figura 15 y 16).

Sobre los paneles informativos, estos se encuentran fijos en el suelo arqueológico mediante una barra de metal. Otra opción que pudo considerarse para su colocación es colocarlos sobre un soporte que permita retirarlos con facilidad de los recintos. No obstante, en su situación actual estos aún pueden ser removidos si la situación lo requiere, cumpliendo los principios de reversibilidad, pero en cuanto a la mínima intervención, los paneles han causado una pequeña afectación (Figura 17).

Además, cabe resaltar la colocación de dos maniquís: uno que representa a un esclavo afrodescendiente de la época, y el otro a una mujer. También en muchos recintos se ha colocado réplicas de botijas. Estas representaciones son una buena opción, pues contribuyen a hacer al yacimiento un poco más didáctico y entretenido visualmente para los visitantes. Lastimosamente los maniquís fueron retirados hace algún tiempo, y quedaron solo las botijas en los recintos del yacimiento.

\section{Conclusiones}

Sobre los puntos resaltantes de la intervención realizada en el yacimiento Bodega y Quadra es posible indicar lo siguiente:

- Resulta destacable la decisión de la gestión municipal de convertir Bodega y Cuadra en un museo de sitio. En nuestro medio lamentablemente no siempre que existe un hallazgo arqueológico se replantean los proyectos, muchas veces prima la importancia del proyecto nuevo y las evidencias terminan siendo rescatadas. Sin embargo, en este caso, la idea original de que fuera parte del Conjunto Habitacional la Muralla cambió.

- El sitio en cuestión se encuentra en una zona del centro histórico de inmejorable accesibilidad, cerca de un área de concentración de personas, la Plaza de Mayor, y de otros inmuebles en buen estado de conservación (se cumple la preservación o conservación ambiental postulada por Salvador Muñoz).

- Se ha mantenido el lazo entre el yacimiento y las piezas a través de la construcción de un museo de sitio, que de otra manera hubieran sido almacenadas o exhibidas en otro lugar.

- Cabe destacar que se dio el uso más adecuado al yacimiento siguiendo el criterio de la restauración objetiva de Antoni Gonzáles Moreno-Navarro. Sobre la propia intervención, si la evaluamos según los principios de la restauración científica de Giovanni Carbonara (distingüibilidad, reversibilidad, autenticidad, mínima intervención y compatibilidad), estos se han cumplido casi en su mayoría.

- El museo de sitio ha retrocedido un poco en su calidad: se ha reducido el circuito turístico en el yacimiento, y se han retirado los maniquíes. Por otro lado, ya es necesaria una intervención para mantener las condiciones de conservación.

\section{Referencias}

Carbonara, G. (1996). Tendencias actuales de la restauración en Italia. Loggia. Arquitectura \& Restauración, (6), 12-23.

Carta de Venecia. (1964). Carta Internacional sobre la Conservación y la Restauración de Monumentos y Sitios. Venecia, Italia: II Congreso Internacional de Arquitectos y Técnicos de Monumentos Históricos.

Empresa Municipal Inmobiliaria de Lima. (2010). Memoria anual del 2010. Lima, Perú: Autor.

Empresa Municipal Inmobiliaria de Lima. (2011). Memoria anual del 2011. Lima, Perú: Autor.

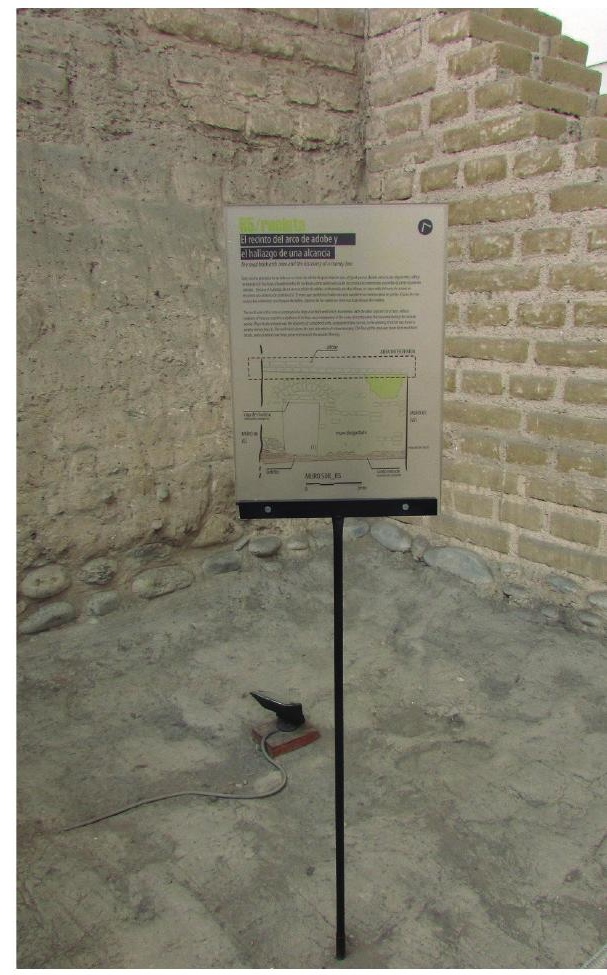

Figura 17. Panel informático del recinto 5

Fuente: Archivo fotográfico personal Rolando Arciga, 2016. 
devenir Vol. 3, N6, JULIO-DICIEMBRE 2016, PP. 31-48 - Estudios I ISSN 2312-7570

UNIVERSIDAD NACIONAL DE INGENIERÍA, LIMA

Empresa Municipal Inmobiliaria de Lima. (2012). Memoria anual del 2012. Lima, Perú: Autor.

Fhon, M. (2014). Arcos y estructuras subterráneas de la época virreinal en la Casa Bodega y Quadra. En R. Chuhue \& P. Van Dalen, Lima Subterránea (pp. 123-134). Lima, Perú: Universidad Nacional Mayor de San Marcos.

Gonzáles, A. (2000). La restauración objetiva (Método SCCM de restauración monumental): Memoria SPAL 1993-1998. Barcelona, España: Diputación de España.

Hampe, T. (2006). La Casa Bodega y Quadra. Gaceta Cultural del Perú. Instituto Nacional de Cultura, 34-35.

Hampe, T. (2008). Juan Francisco de la Bodega y Quadra, descubierto de la Isla de Vancouber. Chasqui, el Correo del Perú. Boletín Cultural del Ministerio de Relaciones Exteriores, (13), 2-3.

Hernández, F. (2007). La museología ante los retos del siglo XXI. e-rph, (1), 1-26.

Muñoz, S. (2003). Teoría contemporánea de la restauración. Madrid, España: Síntesis.

Orrego, J. (2009). Informe del proyecto"Restauración y puesta en valor Casa Bodega y Quadra" Centro Histórico de Lima. Lima, Perú: Empresa Municipal Inmobiliaria de Lima. 